\title{
Clinical uses and toxicity of Atropa belladonna; an evidence based comprehensive retrospective review (2003-2017)
}

\author{
Hanine Almubayedh', Reem Albannay ${ }^{1}$, Kawthar Alelq ${ }^{1}$, Rizwan Ahmad ${ }^{2 *}$, Niyaz Ahmad ${ }^{3}$ \\ and Atta Abbas Naqvi ${ }^{4}$ \\ ${ }^{1}$ College of Clinical Pharmacy, Imam Abdulrahman Bin Faisal University, Dammam, Saudi Arabia \\ ${ }^{2}$ Natural Products and Alternative Medicines, College of Clinical Pharmacy, Imam Abdulrahman Bin Faisal \\ University, Dammam, Saudi Arabia \\ ${ }^{3}$ Department of Pharmaceutics, College of Clinical Pharmacy, Imam Abdulrahman Bin Faisal University, \\ Saudi Arabia \\ ${ }^{4}$ Department of Pharmacy Practice, College of Clinical Pharmacy, Imam Abdulrahman Bin Faisal University, \\ Saudi Arabia
}

\begin{abstract}
Atropa belladonna (AB), commonly known as deadly nightshade is a poisonous plant which contains several alkaloids such as atropine and scopolamine etc. Any deliberate as well as unintentional ingestion of AB fruits, roots or leaves may result toxicity. Aim of the study: This study aims to present the clinical uses of atropine alongwith the adverse effects and toxicity associated with the use of atropine in the form of conventional or as herbal medication. A retrospective (2003-2017) literature was searched in various databases such as web of science, PubMed, google scholar, Scopus, E-Resource Portal of Imam Abdulrahman bin Faisal University etc. using the keywords i.e. $\mathrm{AB}$, clinical uses of $\mathrm{AB}$, adverse effects and cases reported with $\mathrm{AB}$. Ten (10) cases met the eligibility criteria where the toxicity was mostly associated with the use of $A B$ fruit, tablets and $A B$ contaminated drinks. Major symptoms observed in these cases were related to Anticholinergic syndrome (ACS); tachycardia, dilated pupils, confusion, flushed dry skin, hallucinations and seizures in some cases alongwith a toxic megacolon. Furthermore, the treatment protocol used widely for ACS consisted of; gastric lavage and the use of Physostigmine as an antidote (antagonizes the central as well as peripheral toxicity of atropine). $\mathrm{AB}$ fruit revealed a vital role as anticholinergic drug, mydriatic agent and as an antidote for OP poisoning, however, its use deprived of medical supervision or in a large quantity, it may cause severe toxicity.
\end{abstract}

KEY WORDS: ATROPA BELLADONNA, CLINICAL USES, TOXICITY, ANTICHOLINERGIC, CASES REPORTED

\section{ARTICLE INFORMATION:}

*Corresponding Author: rizvistar_36@yahoo.com Received $12^{\text {th }} \mathrm{Feb}, 2018$

Accepted after revision $25^{\text {th }}$ March, 2018

BBRC Print ISSN: 0974-6455

Online ISSN: 2321-4007 CODEN: USA BBRCBA

- Thomson Reuters ISI ESC / Clarivate Analytics USA and

Crossref Indexed Journal

NAAS Journal Score 2017: 4.38 SJIF 2017: 4.196

- A Society of Science and Nature Publication, Bhopal India 2018. All rights reserved.

Online Contents Available at: http//www.bbrc.in/

DOI: $10.21786 / \mathrm{bbrc} / 11.1 / 6$ 


\section{INTRODUCTION}

Solanaceae, an alkaloidal containing plants family, is well known for its applications in cosmetics, traditional medicines and as a poison since ancient times. Atropa belladonna, synonym; deadly nightshade, belongs to the family solanaceae and is known for its effects on "increase pupil size" which imparted it the name of "beautiful lady" (Atropa; Greek word means "goddess" \&t Belladonna; Italian words means "beautiful lady"). It is a tall plant that can reach up to five feet and it's abundantly found in waste ground and quarries. $A B$ has oval shaped leaves, greenish to purple color flowers and black, globular shape, sweet berries. Though leaves and roots are poisonous and ingestion of a single leaf can cause severe ACS which may be fatal, however the berries have been reported with more poisonous cases in children due to its attractive look and sweet taste. The major components in the leaves, fruits and roots are mostly alkaloids such as Hyoscyamine, scopolamine and more abundantly; atropine, which is responsible for the plant's Anti-cholinergic toxic effects, (Berdai et al., 2017; Ahmad et al., 2017a).

Atropa belladonna plant is surrounded by fear, awe, and myth. The Romans and Greeks believed the fact of $\mathrm{AB}$ containing a deadly poison due to more wide use by professional poisoners, sorcerors, and witches. Later on, Linnaeus codified its remarkable properties such as dilating the pupils and it was 1830s, when I-atropine, the pure alkaloid, was extracted from AB plant. It was pure I-atropine that helped as a substantial tool in understanding the physiology of autonomic nervous system and lead to identification of the important neurotransmitters in mammalian biological system which is acetylcholine, (Lee, 2007; Ahmad et al,. 2017b).

Deadly nightshade exerts clinical as well as toxic effects through an anticholinergic mechanism in human body, which can affect the central and the peripheral nervous system. It is responsible for many symptoms such as tachycardia, dry skin, hallucination, mydriasis and choreoathetoid movements. On the other side it may be clinically useful when used to do anamneses in clinical examination as well as detailed imaging in cases which are confused with acute cerebrovascular events. Atropa belladonna poisoning should be considered when diagnosing geriatric patients experiencing hallucination, meaningless hand gestures and consciousness. (Saritas et al., 2014; Ahmad et al., 2017c)

Atropa belladonna poisoning has been reported in different age groups however the most dangerous part of $A B$ to children is its berries especially younger than six years' children, as they have a sweet taste and look attractive to them. (Milanlioglu, 2011).Toxicity may develop as a result of the ingestion of two to three bays of $A B$ in a child and ten bays in an adult. The most common cause of $A B$ intoxication in children is confusion with some other berries such as blueberries and blackcurrant.(Berdai et al., 2012).

Atropa belladonna toxicity can be classified as mild, moderate and severe intoxication. Various treatment plan, depending the severity and condition of the patients, are used for treatment of Atropa belladonna intoxication including gastric lavage and Neostigmine and Physostigmine, as an antidote. (Caksen et al., 2003; Ahmad et al., 2017c)

Numerous literature is available regarding the clinical uses, adverse effects and toxicity cases of $A B$; however none of the studies have reported a complete and updated review about the comparative effects of $A B$ in treating various conditions and the adverse effects of toxicity thus reported. Current study highlight evidencebased clinical uses alongwith toxicity observed with $A B$ use and the most common reason of toxicity i.e. due to intentional or unintentional use of atropine tablets, barriers, leaves or plant as a whole.

\section{MATERIAL AND METHODS}

\section{DATABASES SEARCHED}

The relevant literature was searched using different databases such as Central library Imam Abdulrahman bin Faisal University, PubMed, Google Scalar, Science Direct and Google scholar, Web of science. In addition, Journals (The American journal of therapeutics, Bali medical journal, Human and experimental toxicology, and journal of the Royal college of physicians of Edinburgh) and books (Lippincott's pharmacology and Katzung's basic, clinical pharmacology and Neuropathy of Drug Addictions and Substance Misuse) were also utilized as tools for gathering related information.

\section{Keywords Searched}

Atropa belladonna, cases reported of Atropa belladonna toxicity, Atropine intoxication, Atropa belladonna intoxication, Deadly nightshade intoxication, Anticholinergic toxic syndrome cases and cases of Atropa belladonna poisoning.

\section{Review Period}

This article used a retrospective fourteen (14) years review from year 2003 to 2017.

\section{Inclusion Criteria}

Clinical cases included in the review are only related to/ reported in human subjects only. Any adverse effect or toxicity resulted due to use of atropine in conventional 
system or herbal system as well as any use related to intentional or unintentional ingestion was included in the study. Furthermore, the toxicity or overdose associated with the use of any part of $A B$ i.e. leaves, fruit and berries as well as contamination/adulteration of herbs with atropine, were also included.

\section{Exclusion Criteria}

Any clinical cases reported in animal subjects and in vitro studies were excluded from the study. Similarly, any case reporting traditional or general uses of $A B$ rather than evidence-based i.e. any clinical case reported to hospital emergencies or clinics were also excluded from the study.

\section{Search Results}

The literature search was refined and a total of eleven (11) articles matched the inclusion criteria and they are reported in the literature review section as below.

\section{LITERATURE REVIEW}

All the relevant cases were collected, studied, analyzed and reported after a broad literature review. The cases are presented below with respect to the year of publication.

\section{CLINICAL CASES REPORTED IN 2017}

$A B$ causing ACS due to adulteration with marshmallow roots

Oerlemans et al., reported a case for a patient visiting ER with ACS. The history revealed ingestion of hot chocolate drink with marshmallow root (Althaea officinalis) for treating cold symptoms. However the lab reports showed ingestion of $20-200 \mathrm{mg}$ of atropine as the herb was contaminated with $\mathrm{Ab}$. The patient after transferring to ICU was discharged in a healthy state. (Oerlemans et al., 2017)

\section{ACS due to use of $A B$ berries}

Ibrahim karagoz et al, in a study reported a patient case from ER with anticholinergic toxic syndrome (ATS) symptoms (tachycardia, dilated pupils and hot reddish extremities and trunk). Upon investigation it was revealed that the patient used 5 to 6 blackberry like berries i.e. $A B$ fruit. Symptoms resolved after application of urine catheter and inhibition of oral intake except for tachycardia. Redness also diminished leaving rashes on his arms. Sinus tachycardia disappeared during followup after oral intake resumed. Patient was discharged healthy from the hospital after the follow-up period. (Karagoz et al., 2017)
Toxic Megacolon devolved secondary to OP poisoning treatment

An old man was admitted to ER with loss of consciousness. The patient consumed pesticides containing organophosphate. The treatment plan consisted of atropine and pralidoxime intravenously however the patient developed a megacolon following 4 days of atropine administration. Atropine and pralidoxime tapering was done and patient was put on a maintenance therapy. The serum cholinesterase reached 3209 microkat/1, after 33 days. (Mostafazadeh et al., 2017).

\section{CLINICAL CASE REPORTED IN 2016}

$\mathrm{AB}$ in homeopathic remedies and ACS

A 20-days old infant was presented in ER with signs of seizures and fever, after swallowing a homeopathic agent containing $\mathrm{AB}$ for an infantile colic treatment. Detailed clinical examination revealed and was treated with Benzodiazepines. In addition $\mathrm{i} / \mathrm{v}$ antibiotics were administered due to septicemia. Several hours following the monitoring, no signs of fever were found and the infant recovered from neurological abnormalities was thus discharged healthy. (Glatstein et al., 2016).

\section{CLINICAL CASE REPORTED IN 2014}

Jimsonweed as a source of suicide

Glatstein et al, (2016) reported a study of ten adolescent cases with serious ACS and two with a history of suicidal attempt. Detailed investigation revealed the use of Jimson weed (atropine containing plant) in half of the patients whereas remaining half of the patients used different atropine tablets. Treatment plan included Physostigmine, activated charcoal, benzodiazepines and haloperidol and all the patients were discharged healthy. (Glatstein et al., 2014; Ahmad et al., 2017a).

\section{CLINICAL CASE REPORTED IN 2013}

Wild fruit of $A B$ vs consciousness

Abdullah Demirhan et al., reported an emergency case for a patient presented with symptoms; loss of consciousness and fatigue, red neck and face, dry mouth and dilated pupils. The care taker for patient revealed the use of large amount of a forest fruit $A B$ and the start of symptoms after four hours of ingestion. Gastric lavage followed by administration of activated charcoal $(1 \mathrm{mg} / \mathrm{kg})$ diminished the symptoms within 24 hours and the patient was discharged healthy. (Demirhan et al., 2013). 
Hanine Almubayedh et al.

\begin{tabular}{|c|c|c|c|c|c|c|}
\hline $\begin{array}{l}\text { Case } \\
\text { No. }\end{array}$ & $\begin{array}{l}\text { Form of Atropine } \\
\text { Ingested }\end{array}$ & Age & Gender & Clinical Manifestation & Treatment Protocol & $\begin{array}{l}\text { Cause of } \\
\text { Ingestion }\end{array}$ \\
\hline 1 & Althaea officinalis & $28 / 27$ & $\begin{array}{l}\text { Female / } \\
\text { Male }\end{array}$ & ACS & - & $\begin{array}{l}\text { Ingestion of } \\
\text { contaminated hot } \\
\text { drink }\end{array}$ \\
\hline 2 & $\mathrm{AB}$ fruit & 71 & Male & $\begin{array}{l}\text {-Tachycardia } \\
\text {-Dilated pupils } \\
\text {-Redness of extremities and trunk }\end{array}$ & - & $\begin{array}{l}\text { Confusion with } \\
\text { blackberry fruit }\end{array}$ \\
\hline 3 & IV Atropine & 52 & Male & Toxic megacolon & $\begin{array}{l}\text { Tapering of Atropine } \\
\text { and Pralidoxime }\end{array}$ & $\begin{array}{l}\text { Treatment for } \mathrm{OP} \\
\text { poisoning }\end{array}$ \\
\hline 4 & $\begin{array}{l}\text { Homeopathic agent } \\
\text { containing } \mathrm{AB}\end{array}$ & 20 days & - & $\begin{array}{l}\text {-Seizures } \\
\text {-Fever }\end{array}$ & - & $\begin{array}{l}\text { Treatment of } \\
\text { infantile colic }\end{array}$ \\
\hline 5 & $\begin{array}{l}\text { Jimsonweed / } \\
\text { Atropine Tablets }\end{array}$ & Adolescents & - & ACS & $\begin{array}{l}\text {-Physostigmine } \\
\text {-Activated charcoal } \\
\text {-Benzodiazepine } \\
\text {-Haloperidol }\end{array}$ & $\begin{array}{l}\text { Two of patients } \\
\text { had them as } \\
\text { suicide attempts }\end{array}$ \\
\hline 6 & $\mathrm{AB}$ fruit & 49 & Female & $\begin{array}{l}\text {-Loss of consciousness } \\
\text {-Fatigue } \\
\text {-Redness of face and neck } \\
\text {-Dilated and isochoric pupils } \\
\text {-Dryness of mouth } \\
\end{array}$ & $\begin{array}{l}\text {-Gastric Lavage } \\
\text {-Activated Charcoal } \\
\text {-Supportive therapy }\end{array}$ & $\begin{array}{l}\text { Confusion with } \\
\text { forest fruit }\end{array}$ \\
\hline 7 & & 11 & Female & $\begin{array}{l}\text {-Confusion } \\
\text {-visual and hearing hallucinations } \\
\text {-uncontrollable vomiting } \\
\text {-incoherent speech }\end{array}$ & Diazepam & $\begin{array}{l}\text { Treatment of } \\
\text { jaundice }\end{array}$ \\
\hline 8 & AB Leaves & 40 & Male & $\begin{array}{l}\text {-Flushed warm skin } \\
\text {-Dry tongue } \\
\text {-Sudden psychomotor agitation } \\
\text {-Disorientation } \\
\text {-Dilated pupils } \\
\text {-Tachycardia }\end{array}$ & $\begin{array}{l}\text {-Activated charcoal } \\
\text {-Diazepam } \\
\text {-Supportive therapy }\end{array}$ & $\begin{array}{l}\text { Treatment of } \\
\text { chronic peptic } \\
\text { ulcer }\end{array}$ \\
\hline 9 & $\mathrm{AB}$ Fruit & 2 & - & Central and Peripheral ACS & & $\begin{array}{l}\text { Confusion with } \\
\text { wild berries }\end{array}$ \\
\hline 10 & - & 48 & Male & $\begin{array}{l}\text {-Tachycardia } \\
\text {-severe disorientation } \\
\text {-Aggressiveness }\end{array}$ & $\begin{array}{l}\text {-Activated charcoal } \\
\text {-Diazepam } \\
\text {-IV Physostigmine }\end{array}$ & - \\
\hline 11 & - & Children & - & $\begin{array}{l}\text {-Tachycardia } \\
\text {-Flushed skin } \\
\text {-Meaningless speech } \\
\text {-Mydriasis }\end{array}$ & Neostigmine & - \\
\hline
\end{tabular}

\section{CLINICAL CASE REPORTED IN 2012}

\section{ATS developed from jaundice treatment}

An eleven-year-old girl was administered with $A B$ for the sake of treating jaundice developed due to use of rifampicin and isoniazid for lymph node treatment. The patient developed ATS with symptoms; confusion, visual and hearing hallucinations, uncontrollable vomiting, and incoherent speech. The treatment plan consisted of diazepam $(5 \mathrm{mg}$ ) for sedation purpose whereas charcoal wasn't administered as $A B$ was ingested a day before.
For treating jaundice the tuberculosis treatment was stopped. (Berdai et al., 2012)

\section{CLINICAL CASE REPORTED IN 2011}

Chronic peptic ulcer treatment causing ACS

A patient was admitted to ER with symptoms; warm and flushed skin, dry tongue, sudden psychomotor agitation, disorientation, dilated pupils and tachycardia. Patient history revealed the ingestion of $A B$ leaves for relieving peptic ulcer. Treatment was successful after administra- 
tion of activated charcoal, diazepam (10mg) and gastric decontamination. (Milanlioglu, 2011).

$\mathrm{AB}$ wild barriers causing central and peripheral Atropine poisoning symptoms

A two year old child after eating wild berries was brought to ER. The plant as presented by his mother was identified to be $A B$ whereas the symptoms observed were both peripheral and central atropine poisoning. Following a proper treatment, the patient was discharged healthy. (Laffargue et al., 2011).

\section{CLINICAL CASE REPORTED IN 2009}

\section{$A B$ Vs ATC}

A forty eight year man ingested three handful of $A B$ and developed symptoms of tachycardia, severe disorientation and aggressiveness, in the first six hours of ingestion. He was treated with diazepam, activated charcoal and Physostigmine (continuous therapy) and was recovered within two days. (Zimmermann et al., 2009)

\section{CLINICAL CASE REPORTED IN 2003}

Severe to mild $A B$ toxicity symptoms in 49 children.

$\mathrm{AB}$ toxicity was reported in forty nine children's in a study. They were divided into two groups i.e. sever intoxication symptoms group (6 child's) and mild to moderate symptoms group (43 child's). The most commonly observed symptoms were; tachycardia, flushed skin, meaningless speech, and mydriasis. Due to lack of Physostigmine availability, Neostigmine was used as an antidote for treatment. No death cases were reported, (Caksen et al., 2003).

\section{DISCUSSION}

Atropa belladonna, known as deadly nightshade, can be very toxic. It has an anticholinergic effect on human body which can affect the central as well as the peripheral nervous systems. The symptoms and its severity may vary among age groups and gender depending upon the ingested dose and patients experience anticholinergic toxic syndrome with different symptoms, (Glatstein et al., 2014; Ahmad et al., 2017a; Ahmad et al., 2017b).

However, the most common symptoms reported in the cases founded in current literature i.e. from 20032017 includes; tachycardia, seizures, dryness of mouth, dilated pupils, hallucinations and confusion. This review underlines the clinical uses as well as any clinical manifestations associated with or any toxicity resulted due to use of atropine in any of its form i.e. plant extract, berries, tablets, powder etc. Generally, the plant $A B$ is considered as a toxic one and using the plant without proper knowledge and guidance may be harmful.

Toxic dose of Atropa belladonna: Atropa belladonna was commonly used by professional poisoners, sorcerors and witches since ages. Mature fruits and green leaves have the highest concentration of atropine whereas the mature fruit is claimed to contain $2 \mathrm{mg}$ of atropine, (Passos et al., 2016) As per Martindale, the mortal dose of atropine is $10 \mathrm{mg}$ (equal to $5 \mathrm{AB}$ fruits) and $100 \mathrm{mg}$ (equal to $50 \mathrm{AB}$ fruits) or less for children and adults, respectively. Duration of action: ACS symptoms start usually within one hour after ingestion and Sub-mortal clinical symptoms may continue for 2 days, (Spina et al., 2007). The severity of ACS/ATS, however, depends upon whether and when medical intervention was taken. (Adamse et al., 2015).

Atropine induced psychosis: as mentioned in the literature review, Atropa belladonna intoxications cause central ATS symptoms which include hallucinations, confusion and psychosis. Psychosis is induced as a result of decrease in acetylcholine transmission, accompanied with an increase in dopamine transmission in the Central nervous system, as their levels are influenced by each other. (Gaudreau et al., 2005). Atropine induced psychosis is explained by the ability of Tropane alkaloids to rapidly cross the blood brain barrier and affect the CNS functions. Having cholinergic blocking effects, atropine can block $M_{1}$ receptors (Ardila et al., 1991) in the brain causing psychosis by the mentioned mechanism. Although central and peripheral ATS have been reported in cases of overdose, rare cases are founded to cause such symptoms at pharmacological doses in sensitive subjects. Baker and Farley reported toxic psychosis caused by atropine eye-drops. The patient was prescribed with 1\% atropine eye-drops in her right eye for the treatment of retinal detachment. Following a treatment of three and half weeks, she developed toxic psychosis and peripheral symptoms of ATS, (Baker, 2010).

Toxic megacolon developed form atropine intoxication: though incidence of atropine-associated toxic megacolon is very rare, however still few cases have reported such complication. These case reports suggested an involvement of atropine in the manifestation of toxic megacolon, (Mostafazadeh et al., 2017; Scharer et al., 1964; Mann et al., 1977). In the first two cases, toxic megacolon developed after the administration of anticholinergic agent and was reversed after the discontinuation of the anticholinergic agent. Although the pathophysiological bases of atropine involvement in toxic megacolon remain unclear, some theories suggest that anticholinergic agents, such as atropine, lead to gastrointestinal peristalsis inactivity and delay intestinal transit time which in turn may have caused toxic megacolon. (Mostafazadeh et al., 2017). 
Memory defects caused by Hyoscine: Hyoscine, also known as scopolamine (an active drug in $\mathrm{AB}$ plant), has been widely used in clinical practice for years. However, many cases of hyoscine toxicities have been reported. Hyoscine toxicity has been associated with ATS as atropine and amnesia. An analysis done after days of hyoscine intoxication, by Ardila and Moreno in 1991, showed significant decrease in logical memory, visual reproduction, digits, associative learning which suggest defects in residual memory after hyoscine intoxications, (Ardila et al., 1991). Although hyoscine induced amnesia has been reported as an intoxication complication, hyoscine helped in inducing amnesia for testing of the anti-amnesic effect in medications and plants such as Ficus religiosa, (Kaur et al., 2010).

In our study we reported $\mathrm{AB}$ intoxication in retrospective years i.e. 2003-2017, in adults, children and adolescents. Almost half of the subjects were adults whereas the other half was children and adolescents. Furthermore, intoxication was produced irrespective of gender however the subjects mostly affected were male. In addition, few of the cases highlighted the use of $\mathrm{AB}$ fruit instead of forest fruit by mistake due to similar appearance. One of the cases reported the use of atropine tablets by adolescent subjects however majority of the case reports suggests the fact; ACS syndrome was associated with the use of $\mathrm{AB}$ fruit/plant for treating various diseases such as Jaundice, peptic ulcer, organophosphate poisoning and infantile colic. The literature review and eleven cases observed during the last fifteen years may not be sufficient evidence to claim a plant as a toxic one and disqualify it. As evident in the previously reported cases, ACS was one of the major drawback observed with the use of $\mathrm{AB}$ plant however lack of any causality or death still favor its use as a medicinal plant. The reported cases showed the use of Ab/atropine for various ailments, hence $\mathrm{AB}$ plays a major role in various conditions till date, as discussed.

Atropine as antidote in Organophosphate poisoning: Atropine has a huge therapeutic value and is widely used as an antidote in cases of organophosphate poisoning. Organophosphates are one of the long acting Ach esterase inhibitors used mainly as war gases. (Katzung et al., 2012) Symptoms of OP poisoning manifest as a result of accumulation of Ach at the nerve junction causing acute cholinergic crisis. Atropine is considered to be an important agent that reverses central and peripheral symptoms of organophosphate poisoning for its central and peripheral anticholinergic affects. (Dong et al., 2017; Kumar et al., 2001; Mustafa et al., 2016).

Atropine in the management of myopia; Atropine is a nonselective anticholinergic agent that can be administrated locally for controlling mild to moderate myopia, which is one of refractive disorders. In the last decade, atropine was used as an evidence-based treatment but the mechanism of action is unknown yet. It is considered to be well effective and tolerated at low doses in the management of low and moderate cases. Atropine has been also used to slow the progression of ocular axial elongation and myopia. Audrey et al., studied the efficacy and safety of atropine in Asian children with myopia. Atropine in this study was very effective and well tolerated in slowing down the advancement of myopia and ocular axial elongation. (Chuang, 2017; Chia et al., 2012; Chua et al., 2006).

Managing Smooth muscle spasms hyoscine is an active constituent in the Buscopan formulation as Hyoscine-n-butyl bromide. Intestinal spasms result from the cholinergic stimulation of smooth muscle in the GIT, which increases its motility and secretions. (Whalen, 2015; Ardila et al., 1991; Zhu et al., 2017). Hyoscine can comfort the pain of bowl and stomach cramps by blocking the $M_{1}$ receptors therefore, blocking the cholinergic effects on the intestinal muscles. In addition, hyoscine is used as cervical antispasmodic agent in labor whereby exert effects via decreasing the duration of first stage in labor, owing to its anticholinergic effects of the smooth muscles of the uterus. (Sirohiwal et al., 2005).

Antiemetic effect of hyoscine: hyoscine also blocks the motility of the smooth muscles as well as their secretions by its anti-muscarinic action. Having these effects, hyoscine can be used to control the vomiting and nausea. A case reported by Brown et al., presented a breast cancer patient having nausea and vomiting which were resistant to the widely available anti-emetics, who was treated successfully with hyoscine transdermal patch. (Fay and Llio, 2016).

To conclude; $A B$ ingestion may induce ACS however not all of the characteristics of ACS may be found in few of the $A B$ poisoning cases. The fact is supported by the presence of hybrid form within $\mathrm{AB}$ plant, (Cikla et al., 2011). The major aim of current review was to search and report any recently observed cases related to $A B$ use and explore the most widely observed and common symptoms of $\mathrm{AB}$ toxicity. The aforementioned cases suggest two types of clinical manifestation i. central nervous system effects (CNS) and ii. Peripheral nervous system effects (PNS). The symptoms presented with CNS includes; short-term memory loss, ataxia, hallucinations, agitated delirium, disorientation, seizures, confusion, psychosis, coma leading towards respiratory failure as well as cardiovascular collapse. PNS symptoms includes; dry mucous membranes, hyperreflexia, mydriasis with cyclopedia, diminished bowel sounds or ileus, flushed skin, hypertension or hypotension, tachycardia and urinary retention. Furthermore, the symptoms in children consisted of; lethargy, meaningless speech, absence of tachycardia and coma. The ACS 
reported in most of the cases was due to use of $A B$ for different treatment purposes including myopia, smooth muscle spasm, jaundice, peptic ulcer and organophosphorus poisoning however all the cases were properly managed with charcoal, gastric lavage and Physostigmine/neostigmine without any death.

\section{CONCLUSION}

Atropa belladonna, as a medicinal plant possesses a huge respect in patient treatment. Every plant, its extract or active drug as well as any conventional medication may produce specific side effects or adverse effects which is commonly associated with the use of these agents. $A B$ produces ACS and the symptoms are properly treated with the available treatments or antidote. However, despite its wide therapeutic uses, $\mathrm{AB}$ if used inappropriately or without any proper medical supervision may be toxic. In addition, lack of proper treatment protocol as well as the antidote i.e. Physostigmine in most of the cases, may exaggerate the toxicity symptoms and lead towards fatal condition.

\section{CONFLICT OF INTERESTS}

No conflict of interest exists among the authors.

\section{FINANCIAL SUPPORT}

No support was provided by any government or private funding agency.

\section{REFERENCES}

Adamse P, van Egmond HP, Noordam MY, Mulder PPJ, de Nijs M (2015). Tropane alkaloids in food: poisoning incidents. Quality Assurance and Safety of Crops \& Foods. 8(4):15-24.

Ahmad R, Ahmad N, Naqvi AA, Shehzad A, Al-Ghamdi MS (2017). Role of traditional Islamic and Arabic plants in cancer therapy. Journal of Traditional and Complementary Medicine 7;195-204.

Ahmad A, Naqvi AA, Ahmad N, Baraka M et al., (2017). Awareness, Perception, Attitude, and Knowledge RegardingComplementary and Alternative Medicines (CAMs) Among the Pharmacy and Medical Students of a Public University in Saudi Arabia. Arch Pharma Pract, 8:51.

Ahmad R, Ahmad N, Naqvi AA (2017). Ziziphus oxyphylla: Ethnobotanical, ethnopharmacological and phytochemical review. Biomedicine \&t Pharmacotherapy 91;970-998.

Ardila A, Moreno C (1991). Scopolamine Intoxication as a Model of Transient Global Amnesia. Brain and cognition. 15(2):236-245.

Baker JP, Farley JD (1958). Toxic Psychosis Following Atropine Eye-Drops. The British Medical Journal. 2:1390-1392.
Berdai MA, Labib S, Chetouani K, Harandou M (2012). Atropa belladonna intoxication: a case report. The Pan African Medical Journal. 11:27.

Caksen H, Odabaș D, Akbayram S, Cesur Y, Arslan S, Uner A, Oner AF (2003). Deadly nightshade (Atropa belladonna) intoxication: an analysis of 49 children. Human \& Experimental Toxicology. 665-668, 22:12.

Chia A, Chua WH, Cheung YB, Wong WL, Lingham A, Fong A, Tan D (2012). Atropine for the Treatment of Childhood Myopia: Safety and Efficacy of 0.5\%, 0.1\%, and 0.01\% Doses (Atropine for the Treatment of Myopia 2). Ophthalmology. 119(2):347-354.

Chuang AYC (2017). How to effectively manage myopia. Taiwan Journal of Ophthalmol. 7(1): 44-47.

Chua WH, Balakrishnan V, Chan YH, Tong L, Ling Y, Quah BL, Tan D (2006). Atropine for the Treatment of Childhood Myopia. Ophthalmology. 114(12):2285-2291.

Cikla U, Turkmen S, Karaca Y, Ayaz AF, Turedi S, Gunduz A (2011). An Atropa belladonna L poisoning with acute subdural hematoma. Human and Experimental Toxicology. 30(12):305.

Demirhan A, Tekelioğlu ÜY,Yıldız İ, Korkmaz T, Bilgi M, Akkaya A, Koçoğlu H (2013). Atropa belladona Fruit (Deadly Nightshade) Related Anticholinergic Toxic Syndrome: A Case Report. Turk J Anaesthesiol Reanim. 41(6):226-228.

Dong H, Weng YB, Zhen GS, Li FJ, Jin AC, Liu J (2017). Clinical emergency treatment of 68 critical patients with severe organophosphorus poisoning and prognosis analysis after rescue. Medicine (Baltimore). 96(25): e7237.

Fay MB, Llion DI (2016). Oesophageal spasm, vomiting and hyoscine hydrobromide patch. BMJ Supportive \& Palliative Care. 6(1):125-127.

Gaudreau JD, Gagnon P (2005). Psychotogenic drugs and delirium pathogenesis: the central role of the thalamus. Medical Hypotheses. 64(3):471-475.

Glatstein M, Alabdulrazzaq F, Scolnik D (2016). Belladonna Alkaloid Intoxication: The 10-Year Experience of a Large Tertiary Care Pediatric Hospital. American Journal of Therapeutics. 23(1): e74-e77.

Glatstein M, Danino D, Wolyniez I, Scolnik D (2014). Seizures Caused by Ingestion of Atropa belladonna in a Homeopathic Medicine in a Previously Well Infant: Case Report and Review of the Literature. American Journal of Therapeutics. 21:e196-e198.

Karagoz I, Bilgi M, Boduc E, Pehlivan M, Solmaz K, Sahin D, Savli H, Aktas G (2017). Atropa belladonna and associated anticholinergic toxic syndrome: a case report. Bali Medical Journal. 2017; 3:S90-S92.

Katzung BG, Masters SB , Trevor AJ. Basic \&t clinical pharmacology (2012). 12th E. London, United Kingdom: Mc Graw Hill medical.

Kaur H, Singh D, Singh B, Goel RK (2010). Anti-amnesic effect of Ficus religiosa in scopolamine-induced anterograde and retrograde amnesia. Pharmaceutical Biology. 48(2):234-240.

Kumar P, Vijayaraghavan R, Singh M (2001). Efficacy of Atropine Nasal Aersol Spray Againts Organophosphosphorous 
Poisoning. Indian Journal of Pharmacology. Indian Journal of Pharmacology, 33(6):431-436.

Laffargue F, Oudot C, Constanty A, Bedu A, Ketterer-Martinon S (2011). Deadly nightshade (Atropa belladonna) intoxication in a 2-year-old child. Archives or Pediatrics \&t Adolescent Medicine. 18(2): 186-188.

Lee MR (2007). Solanaceae IV: Atropa belladonna, deadly nightshade. The journal of the Royal college of physicians of Edinburgh. 27:77-84.

Mann NS, Sachdev AJ (1977). Transient megacolon after gastroscopy. Southern Medical Journal. 70(6):755-756.

Milanlioglu A (2011). Toxic encephalopathy after Atropa belladonna poisoning. Pak J Med Sci. 27(4):926-928.

Mostafazadeh B, Farzaneh E, Paeezi M, Nikkhah F (2017). Toxic megacolon as a rare complication following atropine therapy due to organophosphate poisoning: A case report. MedicoLegal Journal. 85(4):221-223.

Mustafa Y, Ahmet S; Ay MO, Gurger M (2016). Organophosphate Poisoning and Intermediate Syndrome. Archives Medical Review Journal. 25(1):70-83.

Oerlemans C, de Vries I, van Riel AJHP (2017). Anticholinergic syndrome caused by contaminated herbal tea; acting swiftly to identify the source. Ned Tijdschr Geneeskd.; 161., D1261.

Passos ID, Mironidou-Tzouveleki M (2016). Neuropathology of Drug Addictions and Substance Misuse. 1. London, United Kingdom: Elsevier.
Sarıtaş A, Korkmaz M, Murat Kurnaz MM (2015). Three Geriatric Patients Presenting with Atropa belladonna (Deadly Nightshade) Poisoning. journal of academic emergency medicine. 5:161-164.

Scharer LL, Burhenne HJ (1964). Megacolon Associated with Administration of an Anticholinergic Drug in a Patient with Ulcerative Colitis. 9(4):268-274. The American Journal of Digestive Diseases.

Sirohiwal D, Dahiya K, DE M (2005). Efficacy of hyoscine-Nbutyl bromide (Buscopan) suppositories as a cervical spasmolytic agent in labour. Australian and New Zealand Journal of Obstetrics and Gynaecology. 45(2):128-129.

Spina SP, Taddei A (2007). Teenagers with jimson weed (Datura stramonium) poisoning. Canadian Journal of Emergency Medicine. 9(6):467-468.

Whalen K (2015). Lippincott's Pharmacology. 6th E. Florida, USA: Wolters Kluwer; p. 56.

Zhu CP, Jiang F, Wang RQ, Guo XZ, Hou XH, Xu H, Zeng Y, $\mathrm{Du}$ YQ, Li ZS (2017). Comparison of efficacy and safety of hyoscine butylbromide versus anisodamine for acute gastric or intestinal spasm-like pain. Journal of Digestive Diseases. 18(8):453-460.

Zimmermann T, Zilker T, Eyer F, Thiermann H (2009). Plasma level of atropine after accidental ingesti on of Atropa belladonna. Clinical Toxicology. 47(6):602-604. pp. 602-4. 